\title{
Regarding "Cerebral Angiography for Evaluation of Patients with CT Angiogram-Negative Subarachnoid Hemorrhage: An 11-Year Experience"
}

W e would like to thank Heit et $\mathrm{al}^{1}$ for their study "Cerebral Angiography for Evaluation of Patients with CT Angiogram-Negative Subarachnoid Hemorrhage: An 11-Year Experience" on the utility of digital subtraction angiography in patients with negative findings on CT angiography and subarachnoid hemorrhage. This is a laudable effort in addressing an issue with great heterogeneity in literature. However, we would like to raise a few questions regarding the article.

First, the statement that all patients with negative findings on CTA should be considered for DSA should be viewed with caution, especially for patients with perimesencephalic hemorrhage (pSAH). The authors reported that 2 aneurysms and 1 case of vasculitis were identified on DSA as causes of pSAH, which were initially missed on CTA. Heit et $\mathrm{al}^{1}$ stated in the "Materials and Methods" section that if an aneurysm was identified by DSA after negative findings on CTA, the CTA was reviewed retrospectively. However, the results of that review were not available in the article. It would be helpful to know the number of cases with positive findings that could be retrospectively seen on CTA with the hindsight of the DSA results. On the other hand, in our own review of the literature, we found very few and questionable cases of pSAH in which imaging was of utility after initial negative findings on CTA. $^{2}$

The authors quoted Delgado Almandoz et $\mathrm{al}^{3}$ to support the utility of follow-up DSA after negative findings on CTA because 1 aneurysm was detected on follow-up. On careful review of that article, in particular Fig $3 B$ (the initial DSA that supposedly missed the 2-mm left superior cerebellar artery branch aneurysm), the aneurysm can be identified when correlated with subsequent DSA (Fig 3D), but the image quality was different, likely due to technical differences. ${ }^{2}$ It would thus be more helpful to review the cases of missed aneurysms responsible for $\mathrm{pSAH}$ reported by Heit et $\mathrm{al}^{1}$ and see whether they could be identified on the initial study in retrospect. On the basis of a literature review, Westerlaan et $\mathrm{al}^{4}$ found that $27 \%$ (19 of 71) of false-negative ruptured intracranial aneurysms could be detected at CTA retrospectively.

http://dx.doi.org/10.3174/ajnr.A4794
In the cases with pSAH caused by vasculitis or reversible cerebral vasoconstriction syndrome (RCVS), it would be unusual for RCVS to present with pSAH. Most of RCVS SAH tends to be convexity sulcal SAH. ${ }^{5}$ Vasospasm, although rare with pSAH, can also occur. The information about whether the 1 patient with SAH diagnosed as RCVS met the diagnostic criteria of SAH would be helpful.

Of further interest are the 16 patients with xanthochromia whose initial CTAs and subsequent DSAs had negative findings. Some publications have recommended the possible use of CTA to replace lumbar puncture in patients with thunderclap headache, and many institutions have used these papers to justify increased use of CTA for this indication. ${ }^{6}$ The absence of angiographic findings in the current study raises questions about that assumption. ${ }^{7}$

The authors' recommendation that all patients with an initial CTA negative for pSAH should continue to undergo DSA needs further evidence and support. The current literature does not strongly support it, and this recommendation needs to be assessed in terms of its cost-effectiveness. ${ }^{8}$

\section{REFERENCES}

1. Heit JJ, Pastena GT, Nogueira RG, et al. Cerebral angiography for evaluation of patients with CT angiogram-negative subarachnoid hemorrhage: an 11-year experience. AJNR Am J Neuroradiol 2016; 37:297-304 CrossRef Medline

2. Kalra VB, Wu X, Matouk CC, et al. Use of follow-up imaging in isolated perimesencephalic subarachnoid hemorrhage: a metaanalysis. Stroke 2015;46:401-06 CrossRef Medline

3. Delgado Almandoz JE, Jagadeesan BD, Refai D, et al. Diagnostic yield of repeat catheter angiography in patients with catheter and computed tomography angiography negative subarachnoid hemorrhage. Neurosurgery 2012;70:1135-42 CrossRef Medline

4. Westerlaan HE, van Dijk JM, van Dijk MJ, et al. Intracranial aneurysms in patients with subarachnoid hemorrhage: CT angiography as a primary examination tool for diagnosis-systematic review and meta-analysis. Radiology 2011;258:134-45 CrossRef Medline

5. Miller TR, Shivashankar R, Mossa-Basha M, et al. Reversible cerebral vasoconstriction syndrome, Part 1: epidemiology, pathogenesis, and clinical course. AJNR Am J Neuroradiol 2015;36:1392-99 CrossRef Medline 
6. McCormack RF, Hutson A. Can computed tomography angiogra-

(1) X. Wu phy of the brain replace lumbar puncture in the evaluation of acute(1) V.B. Kalra onset headache after a negative noncontrast cranial computed to(1) H.P. Forman mography scan? Acad Emerg Med 2010;17:444-51 CrossRef Medline

7. Malhotra A, Wu X, Kalra VB, et al. Cost-effectiveness analysis of follow-up strategies for thunderclap headache patients with negative non-contrast CT. Acad Emerg Med 2016;23:243-50 CrossRef Medline

8. Kalra VB, Wu X, Forman HP, et al. Cost-effectiveness of angiographic imaging in isolated perimesencephalic subarachnoid hemorrhage. Stroke 2014;45:3576-82 CrossRef Medline 